\title{
Development and Validation of a Indonesian translate Brief Adolescents Subjective Wellbeing in School Scale
}

\author{
M Ahkam A \\ Doctoral Program at the Faculty of Psychology, Universitas Airlangga \\ Faculty of Psychology, Universitas Negeri Makassar \\ m.ahkam.a.s.psi-2016@psikologi.unair.ac.id \\ m.ahkam.a@unm.ac.id \\ Dewi Retno Suminar \\ Faculty of Psychology, Universitas Airlangga \\ dewi.suminar@psikologi.unair.ac.id, \\ Nurainy Fardana Nawangsari \\ Faculty of Psychology, Universitas Airlangga \\ nurainy.fardana@psikologi.unair.ac.id
}

\begin{abstract}
The purpose of this research is to adapt the Brief adolescents' subjective wellbeing in BASWBSS school and to analyze the psychometric properties of the BASWBSS in Indonesian samples. BASWBSS development consists of two components, namely cognitive and affective. The research subjects were 275 students in four high school schools in Surabaya. The psychometric properties of the items are generally adequate with a good estimate of the loading factor. In the dimension of satisfaction at school, the estimated loading factor is 0.60 to 0.82 . The dimension of affect in schools is the estimated value of the loading factor from 0.76 to 0.81 . The first-order CFA model showed a good fit with $\mathrm{P}>0.05=0.046, \mathrm{RMSEA}=0.047, \mathrm{GFI}=0.94, \mathrm{CFI}=0.99, \mathrm{SRMR}=0.04$. Construct reliability on satisfaction at school is 0.887 and the impact dimension at school is 0.762 .
\end{abstract}

Keywords: satisfaction at school, affect at school, students.

Received 9 November 2020/Accepted 9 March 202I @Author all rights reserved

\section{Introduction}

High welfare in schools for students can affect the process of receiving effective information, and help students interact with other students to be healthier and provide benefits for themselves and others (Elias, 2004). Conversely, low school welfare can have an impact on impaired concentration in class (Huebner \& Gilman, 2007), and student psychology such as laziness, stress, negative behavior, and results. academic (Ahkam et al., 2020).

Wellbeing in school is a student's assessment of comfort when in school which, includes a cognitive component and an affective component (Tian et al., 20I3; Tian, Du, et al., 20I5; 
Tian, Zhao, et al., 2015; Tian, Zhang, et al., 20I5). The cognitive component refers to satisfaction at school which is described by students' experiences at school while the affective component is related to positive emotions and negative emotions of students while at school (Tian et al., 2013).

There are several concepts and measurements about welfare in schools that have been used in previous research, including the school wellbeing profile questionnaires (Konu, 2002). The school wellbeing questionnaires were made based on the concept of 'welfare' in the sociological tradition Allard with indicators of wellbeing are divided into four categories: school conditions (having), social relationships (loving), means for self-fulfillment (being) and health status. 'Means (Konu, 2002). The instrument has been widely used, including elementary students and secondary schools in Finland (Konu \& Lintonen, 2006). This instrument has used several aspects but ignores the psychological aspects of students. Although several studies in Indonesia have used the school wellbeing profile questionnaires including Noviyanti and Kumalasari (2020), for students in Jakarta, Ahkam and Arifin (2017), for students in Makassar, will but the instrument used uses translation into Indonesian without explaining the adaptation process being carried out.

Another instrument that has been used to measure welfare in schools is the Adolescents' Subjective Wellbeing in School Scale (ASWBSS) proposed by Tian in 2008 (Tian et al., 20I3). ASWBSS consists of 3 (three) components, namely school satisfaction, positive affect in school, negative affect in school and this scale totals 50 items (Tian et al., 20I3). ASWBSS has high reliability and has been used in several studies including research by Tian et al. (20I3), in junior and senior high school students, and in the research of Sun, et al (20I4), on students at several universities in China. Furthermore, Tian (2015) developed and validated the instrument on the ASWBSS scale to become the Brief adolescents' subjective wellbeing in school (BASWBSS). The development of BASWBSS is carried out by using explanatory factor analysis and confirmatory factor analysis by explaining that the construct of welfare at school for students has 2 (two) (components) including the satisfaction component in school which consists of 6 (six) items and affect in schools which consists of 2 (two) items (Tian, Wang, et al., 20I5). BASWBSS has promising psychometric properties and is recommended for use in a sample of adolescents (Tian, Wang, et al., 20I5). BASWBSS has 
been used in several studies including research (Tian, Zhao, et al., 20I5), on junior high school students and high school students in China, (Liu et al., 2016), on children and adolescents. in China, (Zhou et al., 2020), in public school students in China. The BASWBSS used in this study has internal consistency reliability and validity.

BASWBSS is an instrument that has promising psychometric properties in several previous studies and has promising psychometric properties (Liu et al., 2016; Tian, Zhao, et al., 20I5). However, these instruments cannot be used directly in different cultures, because they can lead to different concepts that require an emphasis on equality, including conceptual, item, semantic, operational, measurement, and functional (Epstein et al., 2015), if used in a different country such as the context of Indonesian youth, cannot immediately be used, requiring adaptation. The aim of this study is to adaptation, a subjective wellbeing in school scale for high school students in Indonesia covering components of satisfaction at school and affect at school. The adaptation of the instruments was carried out so that BASWBSS could be used in Indonesia.

\section{Method}

The research subjects were 275 high school students in the city of Surabaya from 4 high schools. The sampling technique uses cluster sampling. Permit to administer the questionnaire was acquired from all the school in advance. The permissions of all the participants were gathered by means of informed concert.

\section{Procedures implemented}

The development of this instrument uses adaptation referring to the International Test Commission (ITC) Guidelines for Test Adaptation (2016) as a guideline. The adaptation process by following several stages including pre-conditions, development of measuring tools (forward translation, forward translation synthesis, backward translation. Synthesis of backward translation, and expert review), confirmation, and administration. 


\section{Precondition}

The stages carried out include 3 (three) things, namely (I) asking permission from the instrument maker by sending a message via email. (2) input a number of content and definitions, in order to fit the measured construct and target population by the expert to follow the instrument to be used by examining items from the content and definition aspects, whether it is the construct to be measured and the target population target; (3) the use of cultural and language biases that are not relevant to the intended use of the target population, so that the items used are free from cultural bias. All items in Indonesian by translators who have good qualifications of Indonesian and English skills, educational background in psychology, and has knowledge of the cultural context in Indonesia.

\section{Forward translation}

This stage is carried out in translating the original version of the measuring instrument into Indonesian or also known as forwarding translation. The translation process is carried out by two people with the criteria of having good English skills as evidenced by the Toefl or IELTS scores. The translator also gets information about the research objectives, operational definitions of all research variables, and target research respondents to help make it easier to understand the research context. Researchers also make a forward translation to facilitate the forward translation used by translators.

\section{Forward translation synthesis}

This process is carried out to make a synthesis of the results of the forward translation by discussing with one of the reviewers who have a background in psychology and have good English language skills to get a translation scale in Indonesian called Synthesis forward translation.

\section{Backward translation}

The next process is to re-translate it to ensure that the Indonesian translation has the same meaning as the original scale version. The re-translation was carried out by two people who had expertise in Indonesian and English and the two translators did not know each other and did not see the original measuring instrument. 
Synthesis backward translation

The results of the backward translation of the two translators were discussed with one reviewer who has a psychological background and has proficiency in English and Indonesian, which is then made a backward translation system.

\section{Expert review}

This staged process is carried out by measuring the equivalence and validity of the content by involving three experts in the field of educational psychology and measurement.

\section{Confirmation}

This stage is carried out by testing the validity of the adapted instrument. The test conducted in this study used factor analysis.

\section{Administration}

The adapted instrument pays attention to the clarity of the instructions used, the time it takes to complete the test, explanations that can motivate the subject to take the test, and the test's objectives.

\section{Data analysis}

To see the validation of the contents of the instrument items were evaluated by 3 (three) experts in the field of psychology and measurement. The assessment of the experts then carried out the calculation of the content validity index (CVI). Polit et al., (2007) et al, take that for a scale judged to have excellent content validity, it would consist of items having an $\mathrm{I}-\mathrm{CVI}$ of .78 or higher and an S-CVI / Ave of .90 or higher.

The next analysis is confirmatory factor analysis (CFA) to test the validity of the constructs (Goodwin \& Leech, 2003). Construct validity is useful for reflecting constructs theoretically (Hair, et al., 2010). The scale used is the Likert scale which produces an ordinal scale, so that the input data uses the polychoric correlation data using the Weighted Least Square method (Jöreskog, 1994). The statistical analysis used to test the construct validity in this study used lisrell 8,7. 


\section{Result}

Item content analysis

Table I describes the results of the content analysis of 3 (three) psychology and measurement experts.

Table I

Item assessment by three experts

\begin{tabular}{llllll}
\hline & Expert I & Expert 2 & Expert 3 & Experts in Agreement & Item CVI \\
\hline Item I & $\sqrt{ }$ & $\sqrt{ }$ & $\sqrt{ }$ & 3 & 1.00 \\
Item 2 & $\sqrt{ }$ & $\sqrt{ }$ & $\sqrt{ }$ & 3 & 1.00 \\
Item 3 & $\sqrt{ }$ & $\sqrt{ }$ & $\sqrt{ }$ & 3 & 1.00 \\
Item 4 & $\sqrt{ }$ & $\sqrt{ }$ & $\sqrt{ }$ & 3 & 1.00 \\
Item 5 & $\sqrt{ }$ & $\sqrt{ }$ & $\sqrt{ }$ & 3 & 1.00 \\
Item 6 & $\sqrt{ }$ & $\sqrt{ }$ & $\sqrt{ }$ & 3 & 1.00 \\
Item 7 & $\sqrt{ }$ & $\sqrt{ }$ & $\sqrt{ }$ & 3 & 1.00 \\
Item 8 & $\sqrt{ }$ & $\sqrt{ }$ & $\sqrt{ }$ & 3 & 1.00 \\
Proportion relevant & $\mathrm{I}, 00$ & $\mathrm{I}, 00$ & $\mathrm{I}, 00$ & Average I-CVI & 1,00 \\
\hline
\end{tabular}

$\mathrm{I}-\mathrm{CVI}$, item-level content validity index; scale-level content validity index, universal agreement method (S-CVI/ $U A)=1,00$; scale-level content validity index, averaging method $(I-C V I / A v e)=1.00$; average proportion of items judged relevant across the three experts $=1.00$.

Furthermore, the construct validity test explains the goodness of fit of the BASWBSS scale adaptation CFA test showing the fit model. The determination of the fit indicator refers to $\mathrm{Hu}$ and Benter (1998) explaining the fit model if it meets the norm criteria listed as Root Mean square Error of Approximation (RMSEA), Goodness of Fit Index (GFI), Adjusted Goodness of Index (AGFI), Comparative Fit Index ( CFI), Standadized Root Mean Residual (SRMR). The results of the CFA test can be seen in table 2 .

Table 2 
BASWBSS Scale Goodness of fit Results

\begin{tabular}{llll}
\hline Goodness of Fit Criteria & Fit Model Norm & Estimation & Result \\
\hline RMSEA & $\leq 0,08$ & 0,047 & Good fit \\
GFI & $\geq 0,90$ & 0,94 & Good fit \\
AGFI & $\geq 0,90$ & 0,88 & Marginal fit \\
CFI & $\geq 0,90$ & 0,99 & Good fit \\
SRMR & $\leq 0,08$ & 0,04 & Good fit \\
\hline
\end{tabular}

The results of the CFA model Fist welfare scale in schools obtained a path diagram which can be seen in Figure I.

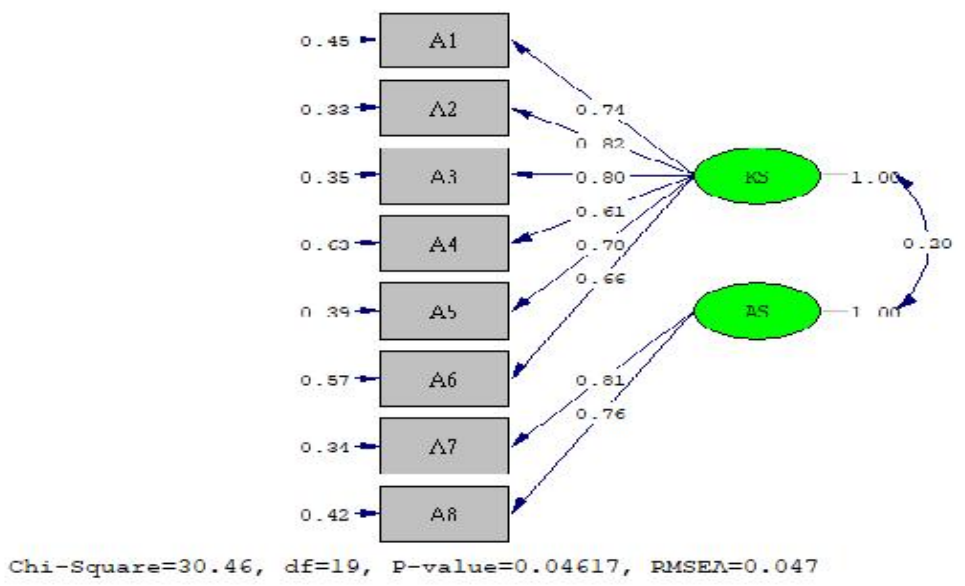

Figure I. CFA BASWSS path diagram

The results of the first order confirmatory analysis of items on the BASWBS scale resulted in a good factor loading above 0.5 (table 4.9). The loading factor value is quite high, between 0.61 to 0.82 on both dimensions of the BASWBSS scale. The dimension of satisfaction at school, the estimated value of the loading factor is quite high, between 0.60 to 0.82 . The dimension of affect in school, the estimated value of the loading factor is quite high, between 0.76 to $0.8 \mathrm{I}$. Complete is presented in table 3. 
Table 3

Loading factor for BASWBSS adaptation scale

\begin{tabular}{lll}
$\begin{array}{ll}\text { No } \\
\text { Item }\end{array}$ & Statements & Factor loading \\
\hline I & I showed good performance in school & 0,74 \\
2 & My school has good school regulations and facilities & 0,82 \\
3 & I have a good relationship with my teachers & 0,80 \\
4 & I have good relations with my classmates & 0,6 I \\
5 & The quality of the teaching methods of the teachers in my school is & 0,78 \\
& good & 0,76 \\
6 & The curriculum and assignments given are reasonable & 0,81 \\
7 & At school, the frequency with which I feel happy is .... & 0,76 \\
8 & At school, the frequency with which I felt bad was ..
\end{tabular}

\section{Reliability}

Furthermore, the reliability analysis using composite reliability (CR) and average variance extracted (AVE) shows the results are reliable. The complete results can be seen in table 4 .

Table 4

Reliability test results

\begin{tabular}{lll}
\hline Aspect & Composite Reliability (CR) & Average variance extracted (AVE). \\
\hline School satisfaction & 0,887 & 0,569 \\
Afek in school & 0,762 & 0,616 \\
\hline Overal & 0,916 & 0,58
\end{tabular}

\section{Discriminant validity}

Discriminant validity is a measurement model that has multiple constructs to see whether each construct is different from one another when measuring a variable (Hair, et al., 2010). The way to test it is determined by comparing the AVE root value with all correlation coefficients between these aspects. If the AVE root value is greater than the correlation 
coefficient, then that aspect has good discriminant validity. The complete results can be seen in table 5 .

Table 5

Discriminant validity

\begin{tabular}{llll}
\hline Aspect & Ave Root & School satisfaction & Affect in school \\
\hline School satisfaction & 0,754 & 1.00 & \\
Affect in school & 0,784 & 0,145 & 1,00 \\
\hline
\end{tabular}

\section{Discussion}

Wellbeing in school is important for students because it is an outcome that determines the quality of education (Van Petegem et al., 2007). Students' assessment of wellbeing in school requires appropriate instruments. The instrument that has been used in several previous studies and has good consistency is the Brief Adolescents' Subjective Wellbeing in School Scale (BASWBSS) (Tian, Wang, et al., 20I5). It is proven that conducting assessments can have an impact on the Brief Adolescents' Subjective Wellbeing in School Scale (BASWBSS) adapted from (Tian, Wang, et al., 20I5), has two dimensions, namely the dimensions of satisfaction at school and affects at school. BASWBSS scale model testing using confirmatory factor analysts in this study using first-order CFA analysis.

The results of the study explain that the components of satisfaction at school and affect at school are the constructs of welfare at school in a sample of high school students. The school satisfaction component consists of 5 (five) items while the affect component in school consists of 2 (two) items. These results are consistent with the research of Liu et al. (2016) previously used The Brief Adolescents' Subjective Wellbeing in School Scale (BASWBSS) instrument which was carried out on a sample of primary and secondary school students in China, and Zhu's research (2019) on a sample of primary schools in China. The results of research in Indonesia also explain that the components of welfare at school for high school students are welfare at school and affect at school (Ahkam et al., 2020). 
The Brief Adolescents' Subjective Wellbeing in School Scale (BASWBSS) in this study was adapted into Indonesian by following the Test Commission (ITC) Guidelines for Test Adaptation (2016) procedure, which is a strict translation process taking into account language, culture, psychology and experts who are relevant to their field. The validity of translation uses an assessment form for comparability and similarity aspects to ensure equality in terms of language back translation results and original items (Sperber, 2004), and to meet equivalence standards in terms of semantics (Epstein et al., 20I5; Hambleton, 2005).

This study also explains that the results of the BASWBSS adaptation analysis have the reliability of internal consistency in the two components, namely the components of satisfaction at school and affect at school. Several previous research results also explain that BASWBSS has the reliability of internal consistency among the studies of Tian, Zhang, Huebner, Zheng, \& Liu, (2016) and Zhu et al (2019), on elementary school students in China, Tian, Pi, Huebner, \& Du (2016), on adolescents in China, Zhou et al (2020), in public school students in China.

In general, this study provides evidence of the adaptation of BASWBSS to a sample of high school students in Indonesia. However, this study has limitations among them, the subjects involved are only in the sample of students in Surabaya and the number is still limited. Therefore it is very interesting to expand the number of research subjects and research locations in several cities in Indonesia. This research can also be extended to the primary and junior high school levels.

\section{Conclusion}

The Brief Adolescents' Subjective Wellbeing in School Scale (BASWBSS) has been adapted by following the adaptation stages involving experts in the fields of psychology and measurement. This adaptation scale is proven to produce good validity after CFA analysis and high reliability. 
Based on the results of high validity and reliability obtained, the adaptation of The Brief Adolescents' Subjective Wellbeing in School Scale (BASWBSS) which consists of 2 (two) dimensions and 8 statements items can be used on high school students in Indonesia.

\section{References}

Ahkam, M. A., \& Arifin, N. A. I. (2017). Optimisme dan school well-being pada mahasiswa. Jurnal Psikologi TALENTA, 137(2), NP-NP. https://doi.org//0.1093/toxsci/kft286

Ahkam, M. A., Dewi, R. S., \& Nawangsari, F. N. (2020). Kesejahteraan di sekolah bagi siswa SMA: Konsep dan faktor yang berpengaruh. Jurnal Psikologi Talenta, 5(2), 97. https://doi.org// 0.26858/talenta.v5i2.11738

Bartram, D., Berberoglu, G., Grégoire, J., Hambleton, R., Muniz, J., \& van de Vijver, F. (20I6). ITC guidelines for translating and adapting tests (Second Edition). International Journal of Testing, I8(2), I0I-I34. https://doi.org/I0.1080/I5305058.20I7.I398I66

Elias, M. J. (2004). Strategies to infuse social and emotional learning into academics. In J. E. Zins, R. P. Weisberg, M. C. Wang, \& H. J. Walberg (Eds.), Building Academic Success on Social and Emotional Learning: What Does the Research Say? (pp. 3-22). Teachers College Press,.

Epstein, J., Santo, R. M., \& Guillemin, F. (2015). A review of guidelines for cross-cultural adaptation of questionnaires could not bring out a consensus. Journal of Clinical Epidemiology, 68(4), 435-44I. https://doi.org/I0.1016/j.jclinepi.20I4.II.02 I

Goodwin, L. D., \& Leech, N. L. (2003). The Meaning of validity in the new standards for educational and psychological testing: Implications for measurement courses. Measurement and Evaluation in Counseling and Development, 36(3), I81-191. https://doi.org//0.1080/0748 I756.2003.1 I90974 I

Hair JR, J. F., Black, W. C., Babin, B. J., \& Anderson, R. E. (2010). Multivariate data analysis (Seventh Ed). Perason Education. Inc. https://linkinghub.elsevier.com/retrieve/pii/S03088|46|7305290

Hambleton, K. R. (2005). Issues, designs, and technical guidelines for adapting tests into multiple languages and cultures. Ronald K. Hambleton, Peter F. Merenda, Charles D. (Eds). Spielberger-Adapting educational and psychological tests for cross-cultural assessment-L. Erlbaum Associ. Lawrence Erlbaum Associates, Inc., Publishers.

Huebner, E. S., \& Gilman, R. (2007). Students who like and dislike school. Applied Research in Quality of Life, I(2), I39-I50. https://doi.org/ I0.1007/s | |482-006-900 I-3

Jiang, H., Sun, P., Liu, Y., \& Pan, M. (20I6). Gratitude and late adolescents' school well-being: the mediating role of materialism. Social Indicators Research, I27(3), I363-1376. 
https://doi.org//0.1007/s I |205-0| 5-1007-5

Jöreskog, K. G. (1994). Structural equation modeling with ordinal variables (Issue 06 February 20I5, pp. 297-310). http://www.ssicentral.com/lisrel/corner.htm. https://doi.org//0.12/4//nms/I2I5463803

Konu, A. (2002). Factor structure of the school well-being model. Health Education Research, I7(6), 732-742. https://doi.org//0.1093/her/17.6.732

Konu, A. I., \& Lintonen, T. . (2006). School well-being in grades 4-I 2. Health Education Research, 2 I (5), 633-642. https://doi.org//0.1093/her/cyl032

Liu, W., Mei, J., Tian, L., \& Huebner, E. S. (2016). Age and gender differences in the relation between school-related social support and subjective well-being in school among students. Social Indicators Research, I25(3), 1065-1083. https://doi.org//0.1007/s I I 2050I5-0873-I

Noviyanti, A., \& Kumalasari, D. (2020). Peran school wellbeing terhadap motivasi sekolah siswa sekolah menengah the role of school wellbeing towards the school motivation of high school students. Jurnal Psikogenesis, 8(I), 78-88. https://doi.org/https://doi.org/I 0.24854/jps.v8il.1228

Polit, D. F., Beck, C. T., \& Owen, S. V. (2007). Focus on research methods is the CVI an Acceptable Indicator of content validity? Appraisal and recommendations. Research in Nursing \& Health,30, 488-495. https://doi.org/I0.1002/nur

Sperber, A. D. (2004). Translation and validation of study Instruments for cross-cultural research. Gastroenterology, I26(I), I24-128. https://doi.org/I0.1053/j.gastro.2003.10.016

Sun, P., Jiang, H., Chu, M., \& Qian, F. (20I4). Gratitude and school well-being among chinese university students: interpersonal relationships and social support as mediators. Social Behavior and Personality: An International Journal, 42(10), 1689-1698. https://doi.org// 0.2224/sbp.2014.42.10.1689

Tian, L., Du, M., \& Huebner, E. S. (2015). The Effect of gratitude on elementary school students' subjective well-being in schools: The mediating role of prosocial behavior. Social Indicators Research, I 22(3), 887-904. https://doi.org/ I 0. I007/s I I 205-0 I4-07 I 2-9

Tian, L., Liu, B., Huang, S., \& Huebner, E. S. (20I3). Perceived social support and school wellbeing among chinese early and middle adolescents: The mediational role of self-esteem. Social Indicators Research, I I3(3), 99 I-1008. https://doi.org/ 10.1007/s I I 205-0 I2-0 I23-8

Tian, L., Wang, D., \& Huebner, E. S. (20I5). Development and validation of the brief adolescents' subjective well-being in school scale (BASWBSS). Social Indicators Research, I 20(2), 6I5-634. https://doi.org/| 0.1007/s | | 205-0 |4-0603-0

Tian, L., Zhang, J., \& Huebner, E. S. (20I5). Preliminary validation of the brief multidimensional students' life satisfaction scale (BMSLSS) among Chinese elementary school students. Child Indicators Research, 8(4), 907-923. 
https://doi.org//0.1007/s /2187-0|4-9295-x

Tian, L., Zhang, L., Huebner, E. S., Zheng, X., \& Liu, W. (2016). The longitudinal relationship between school belonging and subjective well-being in school among elementary school students. Applied Research in Quality of Life, I I (4), I269-I 285.

https://doi.org// 0.1007/s I I482-015-9436-5

Tian, L., Zhao, J., \& Huebner, E. S. (20I5). School-related social support and subjective wellbeing in school among adolescents: The role of self-system factors. Journal of Adolescence, 45, I38-148. https://doi.org/10.1016/j.adolescence.2015.09.003

Van Petegem, K., Aelterman, A., Van Keer, H., \& Rosseel, Y. (2007). The influence of student characteristics and interpersonal teacher behaviour in the classroom on student's wellbeing. Social Indicators Research, 85(2), 279-29I. https://doi.org/| 0.1007/s I | 205-007-9093-7

Zhou, J., Huebner, E. S., \& Tian, L. (2020). Longitudinal associations and mechanisms between achievement goals and subjective well-being in school in Chinese adolescents. School Mental Health, I2(2), 353-365. https://doi.org// 0.1007/s I23 I0-019-09356-8

Zhu, X., Tian, L., Zhou, J., \& Huebner, E. S. (2019). The developmental trajectory of behavioral school engagement and its reciprocal relations with subjective well-being in school among Chinese elementary school students. Children and Youth Services Review, 99(February), 286-295. https://doi.org/10.1016/j.childyouth.2019.01.024 